\title{
Biomarkers in lung cancer screening: a narrative review
}

\author{
Hannah N. Marmor ${ }^{1}$, J. Tyler Zorn ${ }^{1}$, Stephen A. Deppen ${ }^{1,2}$, Pierre P. Massion ${ }^{3,4}$, Eric L. Grogan ${ }^{1,2}$ \\ ${ }^{1}$ Department of Thoracic Surgery, Vanderbilt University Medical Center, Nashville, TN, USA; ${ }^{2}$ Department of Thoracic Surgery, Tennessee Valley \\ VA Healthcare System, Nashville, TN, USA; ${ }^{3}$ Vanderbilt Ingram Cancer Center, Nashville, TN, USA; ${ }^{4}$ Department of Allergy, Pulmonary, and \\ Critical Care Medicine, Vanderbilt University Medical Center, Nashville, TN, USA \\ Contributions: (I) Conception and design: All authors; (II) Administrative support: All authors; (III) Provision of study materials or patients: None; \\ (IV) Collection and assembly of data: None; (V) Data analysis and interpretation: None; (VI) Manuscript writing: All authors; (VII) Final approval of \\ manuscript: All authors. \\ Correspondence to: Eric L. Grogan, MD, MPH. Department of Thoracic Surgery, Vanderbilt University Medical Center, 609 Oxford House, $131321^{\text {st }}$ \\ Avenue South, Nashville, TN 37232, USA. Email: eric.grogan@vumc.org.
}

\begin{abstract}
Although when used as a lung cancer screening tool low-dose computed tomography (LDCT) has demonstrated a significant reduction in lung cancer related mortality, it is not without pitfalls. The associated high false positive rate, inability to distinguish between benign and malignant nodules, cumulative radiation exposure, and resulting patient anxiety have all demonstrated the need for adjunctive testing in lung cancer screening. Current research focuses on developing liquid biomarkers to complement imaging as non-invasive lung cancer diagnostics. Biomarkers can be useful for both the early detection and diagnosis of disease, thereby decreasing the number of unnecessary radiologic tests performed. Biomarkers can stratify cancer risk to further enrich the screening population and augment existing risk prediction. Finally, biomarkers can be used to distinguish benign from malignant nodules in lung cancer screening. While many biomarkers require further validation studies, several, including autoantibodies and blood protein profiling, are available for clinical use. This paper describes the need for biomarkers as a lung cancer screening tool, both in terms of diagnosis and risk assessment. Additionally, this paper will discuss the goals of biomarker use, describe properties of a good biomarker, and review several of the most promising biomarkers currently being studied including autoantibodies, complement fragments, microRNA, blood proteins, circulating tumor DNA (ctDNA), and DNA methylation. Finally, we will describe future directions in the field of biomarker development.
\end{abstract}

Keywords: Biomarkers; lung cancer; screening; diagnosis; early detection

Received: 29 October 2020; Accepted: 04 December 2020; Published online: 01 March 2021.

doi: $10.21037 /$ ccts-20-171

View this article at: http://dx.doi.org/10.21037/ccts-20-171

\section{Background}

Lung cancer remains the leading cause of cancer-related death in the world. In 2018, there were 2.09 million new cases of lung cancer globally accounting for $11.6 \%$ of total cancer cases and 1.76 million deaths from lung cancer globally accounting for $18.4 \%$ of total cancer deaths (1). In the United States, there have been long-term declines in lung cancer death rates between 2008 and 2017, largely due to declines in smoking as well as improvements in early detection and treatment. However, lung cancer continued to cause more deaths in 2017 than breast, prostate, colorectal, and brain cancers combined. This low survival is reflective of the large proportion of patients diagnosed with metastatic disease $(57 \%)$ as opposed to localized disease (15\%) (2-4). As a consequence of asymptomatic cancer growth, most lung cancers go undiagnosed until reaching an advanced stage. Localized disease is potentially curable with resection. Therefore, a significant difference between 5 -year survival of stage 1 disease $(59.5 \%)$ and metastatic disease (5.2\%) exists (5). Therein lies the importance of lung cancer screening with its proven stage shift, earlier 
diagnosis, and curability through resection in high risk individuals $(3,6)$.

The National Lung Screening Trial (NLST), a large multicenter randomized control trial published in 2011, evaluated low-dose computed tomography (LDCT) as a lung cancer screening tool. The study compared annual LDCT versus annual chest radiography for three years in patients aged 55 to 74 who were either current or former smokers with a $\geq 30$ pack-year history. The NLST demonstrated LDCT was associated with a $20 \%$ reduction in lung cancer related mortality. Additionally, the absolute risk of mortality from lung cancer dropped from $1.66 \%$ to $1.33 \%$. This corresponded with a number needed to screen of $320(3,7)$.

While screening with LDCT scans has demonstrated a reduction in lung cancer related mortality, it is not without problems. The LDCT arm of the NLST identified nodules in $24.2 \%$ of patients, however only $1.1 \%$ of these patients had lung cancer (3). Across three rounds of the study, $96.4 \%$ of the positive results in the LDCT group were false positive results (7). With the increase in detection of benign pulmonary nodules there follows an increase in unnecessary, costly, and invasive procedures. According to the National Health Interview Survey (NHIS) conducted in 2015, only $3.9 \%$ of eligible smokers reported LDCT screening in the past 12 months (8). This low utilization of lung cancer screening among eligible patients may be due to fears of overdiagnosis, patient and physician anxiety regarding indeterminate pulmonary nodules, and subsequent invasive testing for benign nodules and cumulative radiation exposure.

Current research is geared towards biomarkers as noninvasive diagnostic tools in lung cancer evaluation. In order to conduct optimal lung cancer screening, it is important to target those individuals at highest risk of disease. Liquid biomarkers can serve multiple roles in lung cancer screening. First, biomarkers can be useful for both the early detection and diagnosis of disease, thereby decreasing the number of unnecessary radiologic tests performed. Second, biomarkers can stratify cancer risk to further enrich the screening population and augment existing risk prediction. At-risk individuals would represent an enriched population or an alternative population for computed tomography (CT) screening, as biomarkers have the ability to reveal those at highest risk of developing lung cancer. Finally, biomarkers can be used to distinguish benign from malignant nodules in lung cancer screening, thereby stratifying individuals with indeterminate pulmonary nodules into high and low risk groups $(9,10)$. Kammer et al. recently validated a lung cancer risk prediction model combining a blood-based biomarker (CYFRA 21-1), imaging biomarker (radiomic signature), and clinical factors (Mayo Clinic Model) (11). While risk prediction models such as the Mayo Clinic Model are commonly used in clinical practice, this work demonstrated an improvement in the diagnostic accuracy of indeterminate pulmonary nodules with a combined clinical risk factor and biomarker approach. An improvement in diagnostic accuracy could bring a reduction in invasive diagnostic procedures as well as a reduction in time to diagnosis for cancer (11).

\section{What makes a good biomarker?}

In this review, we will focus on several of the most promising biomarkers in the literature. However, before we can begin this discussion, we must first describe what makes a good biomarker. The purpose of a biomarker is to aid in the early diagnosis of disease, as well as risk prediction. Therefore, a good biomarker should positively influence clinical decision-making while minimizing harm and expense. Ideally, a clinically useful biomarker ultimately leads to decreases in the number of lung cancer-related deaths (12). A strong biomarker should be easily measurable, accurate, reproducible, and inexpensive (13). Furthermore, a clinically suitable biomarker should be developed using a population it would serve. A valuable diagnostic test must be able to classify a patient as either having a disease (sensitivity) or not having a disease (specificity). Additionally, positive and negative predictive values are of equal importance; it is necessary to be able to discern those patients with a positive test who actually have the disease and those with a negative test who truly are disease-free (14). For example, when using a biomarker for risk prediction of a disease with low prevalence, a strong negative predictive value (NPV) would be particularly valuable (13).

There are several different clinical sources of biomarkers, including blood, airway epithelium, sputum, exhaled breath condensate, and urine (15). Table 1 summarizes a current selection of blood-based biomarkers in lung cancer screening including targets, clinical purpose, and critical diagnostic measures such as sensitivity, specificity, positive predictive value (PPV), and NPV. In this review, we will discuss the different types of existing biomarkers. We will focus on the most promising in the literature based upon the general criteria set out by Mazzone and colleagues (33). 
Table 1 Selected blood-based biomarkers

\begin{tabular}{|c|c|c|c|c|c|c|c|c|c|c|c|c|}
\hline Reference & Specimen & $\begin{array}{c}\text { Biomarker } \\
\text { category }\end{array}$ & Target & Clinical purpose & Development phase & $\begin{array}{c}\text { Training set } \\
\text { (cases/controls) }\end{array}$ & $\begin{array}{l}\text { Validation set } \\
\text { (cases/controls) }\end{array}$ & $\begin{array}{l}\text { Sensitivity } \\
(\% ; 95 \% \mathrm{Cl})\end{array}$ & $\begin{array}{l}\text { Specificity } \\
(\% ; 95 \% \mathrm{Cl})\end{array}$ & PPV (\%) & NPV (\%) & Reported result \\
\hline Boyle (16) & Serum & Autoantibodies & 6 AAB: p53, NY-ESO-1, CAGE, GBU4-5, Annexin 1, and SOX2 & Diagnosis & Clinical validation & $241 /-$ & $255 /-$ & $37^{d}$ & $90^{d}$ & $8^{k}$ & $99^{k}$ & $\begin{array}{l}\text { Any one or more AAB signal } \\
\text { elevated using accepted cut-off }\end{array}$ \\
\hline Chapman (17) & Serum & Autoantibodies & 7 AAB: p53, NY-ESO-1, CAGE, GBU4-5, SOX2, HuD, MAGE A4 & Diagnosis & Clinical validation & $\begin{array}{l}235 / 266 \\
\text { (optimization set) }\end{array}$ & $\begin{array}{l}836 / \text { - (clinical } \\
\text { population set) }\end{array}$ & $47^{\mathrm{a}}$ & $90^{a}$ & $10^{\prime}$ & $99^{\prime}$ & $\begin{array}{l}\text { Any one or more AAB signal } \\
\text { elevated using accepted cut-off }\end{array}$ \\
\hline Jett (18) & Serum & Autoantibodies & $\begin{array}{l}7 \text { AAB: p53, NY-ESO-1, CAGE, GBU4-5, SOX2, HuD, MAGE A4; } 6 \\
\text { AAB: p53, NY-ESO-1, CAGE, GBU4-5, Annexin I, SOX-2 }\end{array}$ & Diagnosis & Clinical validation & NA & $\begin{aligned} & 1,613^{\mathrm{b}}(6 \mathrm{AAB} \\
= & 752)(7 \mathrm{AAB}=861)\end{aligned}$ & $37[21-55]^{\circ}$ & $91[89-93]^{\circ}$ & 16 & 97 & $\begin{array}{l}\text { Any one or more AAB signal } \\
\text { elevated using accepted cut-off }\end{array}$ \\
\hline Wang (19) & Plasma & Autoantibodies & 5 AABs: TTC14, BRAF, KLF8, TLK1, KRT8 & Diagnosis of IPN ${ }^{s}$ & Clinical validation & $40 / 40$ & $97 / 170$ & 30 & 88 & $\mathrm{NA}^{\mathrm{m}}$ & $\mathrm{NA}^{\mathrm{m}}$ & $\begin{array}{l}\text { Any one or more AAB signal } \\
\text { elevated using accepted cut-off }\end{array}$ \\
\hline Ajona (20) & Plasma & $\mathrm{c} 4 \mathrm{~d}$ & C4d levels & Diagnosis of IPN ${ }^{\mathrm{s}}$ & Analytical validation & $59 / 79$ & $148 / 92$ & $44^{\mathrm{d}}$ & $89^{d}$ & 54 & 84 & Unable to assess \\
\hline Sozzi (21) & Plasma & miRNA & 24 miRNA signature classifier & $\begin{array}{l}\text { Diagnosis and } \\
\text { prediction }\end{array}$ & Clinical validation & NA & $69 / 870$ & 87 & 81 & 27 & 99 & Risk score \\
\hline Montani (22) & Serum & miRNA & $\begin{array}{l}13 \text { signature miR-Test: miR-92a-3p, miR-30b-5p, miR-191-5p, miR- } \\
\text { 484, miR-328-3p, miR-30c-5p, miR-374a-5p, let-7d-5p, miR-331- } \\
\text { 3p, miR-29a-3p, miR-148a-3p, miR-223-3p, miR-140-5p }\end{array}$ & $\begin{array}{l}\text { Target "high-risk" } \\
\text { population }\end{array}$ & Clinical validation & $12 / 12$ & $36 / 1,055$ & $78[64-91]^{d}$ & $75[72-78]^{d}$ & $10^{\mathrm{d}}$ & $99^{d}$ & Risk score \\
\hline Doseeva (23) & Serum & $\begin{array}{l}\text { Proteins and } \\
\text { autoantibody }\end{array}$ & 3 proteins and 1 AAB: CEA, CA-125, CYFRA 21-1, NY-ESO-1 & Diagnosis & Clinical validation & $115 / 115$ & $75 / 75$ & $77^{\mathrm{d}}$ & $80^{d}$ & $7^{n}$ & $99^{n}$ & Multiple of median \\
\hline Mazzone (24) & Serum & $\begin{array}{l}\text { Proteins and } \\
\text { autoantibody }\end{array}$ & 4 proteins and 1 AAB: CEA, CA-125, CYFRA 21-1, HGF, NY-ESO-1 & Diagnosis & Clinical validation & 268/336 & $155 / 245$ & $49^{d}$ & $96^{d}$ & $5^{\circ}$ & $96^{\circ}$ & Multiple of median \\
\hline Silvestri (25) & Plasma & Proteins & 2 proteins: LG3BP and C163A & Diagnosis of IPN ${ }^{s}$ & Clinical validation & NA & 29/149 & $97[82-100]$ & 44 [36-52] & 25 & 98 & Integrated classifier \\
\hline Vachani (27) & Plasma & Proteins & 5 proteins: ALDOA, COIA1, FRIL, LG3BP, and TSP1 & Diagnosis of IPN ${ }^{s}$ & Clinical validation & NA & $78 / 63$ & 92 & 20 & $26^{\circ}$ & $90^{\circ}$ & Multivariate classifier \\
\hline Trivedi (28) & Plasma & Proteins & 3 proteins: EGFR, ProSB, TIMP1 & Diagnosis of IPN ${ }^{\mathrm{s}}$ & Clinical validation & $-r$ & $49 / 48$ & 94 & 33 & $32^{9}$ & $94^{9}$ & Risk score \\
\hline Cohen (29) & Plasma & $\begin{array}{l}\text { Proteins and } \\
\text { ctDNA }\end{array}$ & $\begin{array}{l}8 \text { proteins and ctDNA: CA-125, CEA, CA 19-9, PRL, HGF, OPN, } \\
\text { MPO, TIMP-1 }\end{array}$ & Diagnosis & Analytical validation & $\mathrm{NA}^{+}$ & $1,005 / 812$ & $59^{\circ}$ & 99 & $\mathrm{NA}^{\mathrm{m}}$ & $\mathrm{NA}^{\mathrm{m}}$ & $\begin{array}{l}\text { Gene mutation or protein } \\
\text { elevation }\end{array}$ \\
\hline Hulbert (30) & Plasma and sputum & DNA methylation & SOX17, TAC1, HOXA7, CDO1, HOXA9, ZFP42 methylation & Diagnosis & Analytical validation & $99 / 41$ & $51 / 19$ & $98^{9} ; 93^{\mathrm{h}}$ & $71^{9} ; 62^{h}$ & $93^{9} ; 86^{h}$ & $89^{9} ; 78^{\mathrm{h}}$ & Methylation panel \\
\hline Weiss (31) & Plasma & DNA methylation & SHOX2 and PTGER4 methylation & $\begin{array}{l}\text { Diagnosis and } \\
\text { diagnosis of IPN }\end{array}$ & Clinical validation & $118 / 212$ & $50 / 122$ & $67^{i}$ & $73^{i}$ & $\mathrm{NA}^{\mathrm{m}}$ & $\mathrm{NA}^{\mathrm{m}}$ & Methylation panel \\
\hline Ooki (32) & $\begin{array}{l}\text { Lung tissue, serum, pleural } \\
\text { effusion, and ascites }\end{array}$ & DNA methylation & CDO1, HOXA9, AJAP1, PTGDR, UNCX, and MARCH11 methylation & $\begin{array}{l}\text { Diagnosis and } \\
\text { prognosis }\end{array}$ & Clinical validation & 90/- & $83 / 42$ & $72^{d}$ & $71^{d}$ & $82^{d}$ & $51^{d}$ & Methylation panel \\
\hline
\end{tabular}

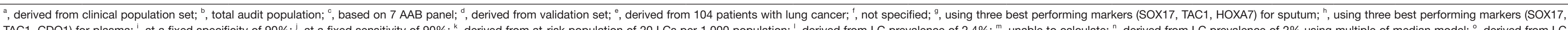

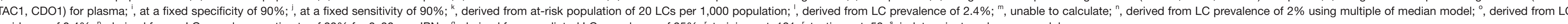




\section{Methods}

We searched PubMed for relevant articles pertaining to biomarkers and lung cancer. Specifically, we searched the database for articles including autoantibodies, complement fragments, microRNA, blood proteins, circulating tumor DNA, or DNA methylation and lung cancer detection, diagnosis, and screening. This search was last updated in October 2020, and supplemented with outside searches of the literature based on collaborators' research experience in this field.

\section{Autoantibodies}

The immune system is made up of the innate and adaptive immune responses. The adaptive immune system consists of both $\mathrm{T}$ and $\mathrm{B}$ cell responses. In cancer, tumor-associated antigens (TAAs) elicit a $\mathrm{T}$ cell response, thereby directly or indirectly killing tumor cells. These TAAs can elicit a B cell response as well, generating the production of autoantibodies (34). These autoantibodies develop in some lung cancer patients, making them useful as potential blood biomarkers for the early detection and diagnosis of cancer as well as distinguishing benign from malignant nodules. For example, if an individual with a CT-identified indeterminate pulmonary nodule tested positive for cancer related serum autoantibodies, the probability of the nodule being malignant would be higher. Additionally, given the high false positive rates associated with CT imaging as a screening tool, autoantibodies have the ability to improve the PPV of screening in those at highest risk of lung cancer (34). One of the challenges in detecting useful cancer screening biomarkers is their relative low quantity in the preclinical stage, as many of the markers are secreted by cancer cells. Autoantibodies would serve as a good biomarker, as the measurement process could utilize targeted amplification of signals from tumor cell proteins (19). Currently, there are multiple autoantibodies being studied as potential lung cancer screening biomarkers. EarlyCDT Lung is commercially available as a blood test designed to identify patients at increased risk for lung cancer in order to better facilitate CT screening (35). EarlyCDT Lung test measures seven autoantibodies: p53, NY-ESO-1, CAGE, GBU45, HuD, MAGE A4, and SOX2. This seven-autoantibody panel was developed after a six-autoantibody panel was modified in 2010 (36). A study conducted by Chapman et al. demonstrated improved sensitivity and specificity of the seven-autoantibody panel (41\% and $91 \%$, respectively) (17).
Massion et al. conducted a registry study in patients with at least one lung nodule and discovered that a positive autoantibody test resulted in a greater than two-fold increase in the relative risk for developing lung cancer (37). A follow-up audit of the EarlyCDT Lung seven autoantibody test performed in routine clinical practice was conducted by Jett $e t a l$. in 2014 . This audit revealed a sensitivity and specificity of $37 \%$ and $91 \%$, respectively, as well as a PPV of $16 \%(18)$.

Additionally, work has been done to utilize autoantibodies in the detection of benign pulmonary nodules from malignant nodules. Wang et al. conducted a study identifying autoantibodies in patients with lung cancer, benign pulmonary nodules, and smoker controls. Comparing autoantibody responses between individuals with lung cancer and those with CT-positive pulmonary nodules demonstrated a five-autoantibody panel (TTC14, BRAF, KLF8, TLK1, and KRT8) with a sensitivity of $30 \%$ at $88 \%$ specificity (19). In summary, autoantibodies serve as a promising bloodbased biomarker for both the early detection and diagnosis of lung cancer; however, their utility in identifying high-risk populations for screening was limited and may only relate to occult malignancy.

\section{Complement fragments}

In addition to the autoantibody response of the adaptive immune system against tumor antigen, lung cancer has the ability to activate the complement cascade of the innate immune system as well (38). A study by Ajona et al. determined lung tumors activate the classical complement cascade, generating $\mathrm{C} 4 \mathrm{~d}$, a degradation product of the classic complement pathway. As a result, these downstream complement fragments are increased in lung cancer patients. The group showed a higher concentration of C4d in bronchoalveolar lavage fluid from patients with lung cancer compared to individuals without lung cancer [area under ROC curve of 0.726 (95\% CI, 61-84.3\%; $\mathrm{P}=0.002)]$. Additionally, $\mathrm{C} 4 \mathrm{~d}$ levels were measured in stage I or II lung cancer patients and control individuals. Plasma samples from individuals with lung cancer revealed higher levels of $\mathrm{C} 4 \mathrm{~d}$ than those without lung cancer (area under ROC curve of $0.782, \mathrm{P}<0.001)$. Furthermore, patients with stage I lung cancer had lower C4d plasma levels than those patients with stage II, and patients with higher levels of $\mathrm{C} 4 \mathrm{~d}$ had a statistically significant shorter overall survival (38). However, when C4d was tested as a biomarker in a set of plasma samples from the Multicenter Italian 
Lung Detection (MILD) trial, it could not differentiate asymptomatic high-risk individuals with or without early stage lung cancer (20).

As a clinical biomarker $\mathrm{C} 4 \mathrm{~d}$ shows greater promise in managing indeterminate pulmonary nodules. Ajona et al. discovered higher levels of $\mathrm{C} 4 \mathrm{~d}$ in patients with lung cancer nodules than those with benign nodules with a sensitivity and specificity of $44 \%$ and $89 \%$. In this same study, C4d plasma levels were used to identify benign versus malignant lung nodules with a PPV of 54\% and a negative predicative value of $84 \%$ (25).

\section{microRNA}

microRNA are small non-coding single-stranded RNA molecules that regulate post-transcriptional gene expression, reflecting tumor-host interactions. Alterations in their expression and frequent deregulations have been linked to the pathogenesis of most human cancers. In fact, shifts in microRNA expression are considered to be characteristic of malignant transformation (39). Additionally, microRNAs are an excellent set of biomarker candidates as they are markedly stable and resistant to degradation. Therefore, they have the ability to travel in bodily fluids for extended lengths of time (21,36,39-41). Montani et al. conducted a validation study using high-risk individuals enrolled in the Continuing Observation of Smoking Subjects (COSMOS) lung cancer screening program, which identified a serum microRNA signature to target an optimal population for LDCT. This 13-microRNA signature, known as the miRTest, includes miR-92a-3p, miR-30b-5p, miR-191-5p, miR-484, miR-328-3p, miR-30c-5p, miR-374a-5p, let-7d5p, miR-331-3p, miR-29a-3p, miR-148a-3p, miR-223-3p, and miR-140-5p. The study demonstrated a sensitivity and specificity of the miR-Test to be $77.8 \%$ (95\% CI, 64.2$91.4 \%$ ) and $74.8 \%$ (95\% CI, 72.1-77.5\%) respectively (22). Sozzi et al. studied the clinical utility of yet another plasma-based microRNA signature classifier (MSC) in a blinded validation study. The MSC categorizes patients into low, intermediate, or high risk of lung cancer based on 24 prespecified microRNA expression ratios. Plasma samples collected from smokers within the MILD trial were analyzed for MSC. The study revealed $87 \%$ sensitivity and $81 \%$ specificity regarding the diagnostic performance of MSC for lung cancer (21). In addition, both the miRNA signature classifier (MSC) and the miR-Test studies demonstrated a reduction in the LDCT false positive rate. These blood-based biomarkers are currently undergoing validation studies (42).

\section{Blood proteins}

There have been multiple studies which have identified serum proteins as potential biomarkers to aid in the early detection, diagnosis, and diagnostic accuracy of lung cancer. Circulating proteins can originate from overexpression on cancer cells, tissue disruption from invasive cancer, increased secretion from diseased tissue, or inflammation associated with malignancy (43). However, these biomarkers also pose several biologic challenges such as low concentrations in the blood for detection and variability in sample collection (44). PAULA's test (Protein Assays Utilizing Lung Cancer Analytes) is currently available for use as a blood test for the early detection of lung cancer as well as risk stratification in high risk individuals (45). This test utilizes a panel of three proteins CEA, CA-125, and CYFRA 21-1 as well as one autoantibody, NY-ESO-1. Doseeva et al. performed a validation study of PAULA's test in a high-risk population which revealed a sensitivity of $71 \%$ and specificity of $88 \%$ (23). Mazzone et al. performed a separate clinical validation study demonstrating a sensitivity and specificity of $49 \%$ and $96 \%$, respectively. In addition, the study demonstrated an improved diagnostic accuracy when incorporating clinical variables with the biomarker panel. The area under the ROC curve was 0.68 when using a model built on clinical variables alone. Using a combination of clinical variables and biomarkers, the area under the curve was 0.86 (24). The PANOPTIC (Pulmonary Nodule Plasma Proteomic Classifier) Trial conducted by Silvestri et al. measured the relative amounts of two plasma proteins, LG3BP and C163A. This two-protein ratio combined with a lung nodule clinical risk prediction model revealed a sensitivity of $97 \%$, specificity of $44 \%$, and NPV of $98 \%$ in distinguishing benign from malignant nodules. Of note, the population included in this study had a clinician assessed pretest probability of malignancy of $50 \%$ or less. Silvestri et al. determined that if this integrated classifier result was used to direct care, $40 \%$ fewer procedures would be performed for benign nodules and 3\% of malignant nodules would be misidentified (25).

\section{Circulating tumor DNA (ctDNA)}

DNA enters plasma through passive (cell necrosis or apoptosis) or active (secretion from living cells) mechanisms. In patients with lung cancer, a portion of the 
cell free DNA in their bloodstream comes from tumor cells undergoing apoptosis and necrosis. This comprises ctDNA which can be used as a biomarker to detect genetic mutation (36). While there have been previous studies demonstrating the role of ctDNA, otherwise known as a liquid biopsy, in identifying advanced-stage cancer as well as surveillance for molecular residual disease after treatment, there is relatively little evidence with regards to its use for the early detection of cancer $(12,46,47)$. A recent study by Cohen et al. described a blood test which measures a combination of eight protein biomarkers and ctDNA to detect eight common early-stage cancers. This blood test is known as CancerSEEK. By combining protein biomarkers and ctDNA, CancerSEEK is able to both detect genetic alterations which can identify early stage cancers as well as localize the origin of disease. The combination of ctDNA and protein biomarkers demonstrated a specificity of $99 \%$ and sensitivity of $59 \%$ for lung cancer in 104 patients $(12,29)$. Recently, Chabon et al. introduced improvements to cancer personalized profiling by deep sequencing (CAPP-Seq). CAPP-Seq is a method used to analyze ctDNA in order to better facilitate lung cancer screening. This study demonstrated that while ctDNA levels were very low in early-stage lung cancers, it was present before the initiation of treatment in most patients. Using these findings in conjunction with other molecular features, this group developed and prospectively validated the machine-learning method Lung Cancer Likelihood in Plasma (Lung-CLiP) to distinguish earlystage lung cancer patients from risk-matched controls with a specificity of $96 \%$ (95\% CI, 89-100\%) (48). Cristiano et al. recently developed a method to evaluate fragmentation patterns of cell-free DNA (cfDNA) present in the genomes of both healthy individuals and those with cancer. They discovered that the cfDNA patterns in healthy patients correlated closely with white blood cell nucleosomal DNA fragmentation patterns. In patients with cancer, however, there existed several genomic differences in the cfDNA with various fragment sizes in different regions. These fragmentation patterns appeared to result from the mixture of both blood and neoplastic cell nucleosomal DNA. This study demonstrated the differences in genomewide cfDNA fragmentation profiles between healthy individuals and those with cancer. When this method was used to analyze fragmentation profiles in 236 patients with breast, colorectal, lung, ovarian, pancreatic, gastric, or bile duct cancer, and 245 healthy individuals, sensitivities of detection ranged from $57 \%$ to $>99 \%$ at $98 \%$ specificity.
Furthermore, these fragmentation profiles identified the cancer tissue of origin to a limited number of sites in $75 \%$ of cases. Again, this study illustrated the potential use for cfDNA in screening and early detection of cancer (49).

\section{DNA methylation}

DNA methylation is an epigenetic modification which adds a methyl group to cytosine predominantly in CpG dinucleotides. Under normal physiologic conditions, this methylation process is tightly regulated. However, alterations in this process such as global hypomethylation, focal hypermethylation of $\mathrm{CpG}$ promoter islands, and direct mutagenesis at methylated cytosines can contribute to chromosomal instability and tumorigenesis (50). With regards to adenocarcinoma of the lung, studies have demonstrated the occurrence of DNA methylation before the formation of atypical adenomatoid hyperplasia (51). As a result, DNA methylation has the potential to be utilized as a biomarker for the early detection of lung cancer. A recent case-control study by Hulbert et al. used a lungcancer specific gene panel to detect DNA methylation in sputum and plasma samples from patients with suspicious nodules on CT imaging preoperatively. The gene panel included SOX17, TAC1, HOXA7, CDO1, HOXA9, and ZFP42. Of these genes, the best performing markers were noted to be SOX17, TAC1, and HOXA7. DNA methylation was detected more frequently in patients with lung cancer compared to controls. The three gene combination of the best performing markers exhibited a sensitivity and specificity of $98 \%$ and $71 \%$ using sputum, and $93 \%$ and $62 \%$ using plasma (30). While DNA methylation is a promising biomarker for the early detection of lung cancer, this class requires further validation studies.

\section{Future directions}

There continues to be an influx of new technologies and emerging biomarkers for the early detection and diagnosis of lung cancer. Several groups are currently looking at exhaled volatile organic compounds (VOCs) as non-invasive biomarkers in the diagnosis of lung cancer. Endogenous VOCs are gaseous organic molecules which are products of different metabolic pathways in the body. Since diseases such as cancer have the ability to alter some of these pathways, it holds true that the associated VOC profile would be affected as well and could serve as a diagnostic biomarker (52). Additionally, biomarkers are being explored 
specifically for use in precision medicine. This so called "omic" data incorporates metabolomics, proteomics, genomics, epigenomics, radiomics, and microbiomics with the goal of further classifying disease to more precisely diagnose and treat lung cancer (53).

As we have seen, LDCT as a lung cancer screening tool has led to a significant decrease in lung cancer related mortality. However, there is a need for adjunctive testing given the suboptimal false positive rates for LDCT. Several of these biomarkers are currently available for commercial use, but many of them require further clinical validation. Specifically, there is a tremendous need for randomized trial studies in biomarker utility testing. While this is both a time and resource intensive endeavor, biomarkers in lung cancer screening have the potential to not only present an enriched population for CT imaging, but aid in the early detection and diagnosis of disease, and distinguish between benign and malignant nodules as well.

\section{Acknowledgments}

Funding: This study was supported by National Institutes of Health grant T32 CA106183-17 to HNM and U01CA152662 to SAD and ELG.

\section{Footnote}

Provenance and Peer Review: This article was commissioned by the Guest Editor (Sandra Starnes) for the series "Lung Cancer Screening" published in Current Challenges in Thoracic Surgery. The article has undergone peer review.

Conflicts of Interest: All authors have completed the ICMJE uniform disclosure form (available at https://ccts. amegroups.com/article/view/10.21037/ccts-20-171/coif). The series "Lung Cancer Screening" was commissioned by the editorial office without any funding or sponsorship. SAD reports grants from National Cancer Institute, during the conduct of the study. The authors have no other conflicts of interest to declare.

Ethical Statement: The authors are accountable for all aspects of the work in ensuring that questions related to the accuracy or integrity of any part of the work are appropriately investigated and resolved.

Open Access Statement: This is an Open Access article distributed in accordance with the Creative Commons
Attribution-NonCommercial-NoDerivs 4.0 International License (CC BY-NC-ND 4.0), which permits the noncommercial replication and distribution of the article with the strict proviso that no changes or edits are made and the original work is properly cited (including links to both the formal publication through the relevant DOI and the license). See: https://creativecommons.org/licenses/by-nc-nd/4.0/.

\section{References}

1. World Health Organization. Cancer fact sheets, lung. 2018. Available online: https://gco.iarc.fr/today/data/ factsheets/cancers/15-Lung-fact-sheet.pdf. Accessed September, 2020.

2. Siegel RL, Miller KD, Jemal A. Cancer Statistics, 2020. CA Cancer J Clin 2020;70:7-30.

3. Bade BC, Brasher PB, Luna BW, et al. Reviewing lung cancer screening: the who, where, when, why, and how. Clin Chest Med 2018;39:31-43.

4. Bade BC, Dela Cruz CS. Lung cancer 2020: epidemiology, etiology, and prevention. Clin Chest Med 2020;41:1-24.

5. National Cancer Institute. Five-year relative and period survival (percent) by race, sex, diagnosis year, stage and age. National Cancer Institute. Available online: https:// seer.cancer.gov/archive/csr/1975_2014/results_merged/ sect_15_lung_bronchus.pdf. Accessed September 2020.

6. Aberle DR, DeMello S, Berg CD, et al. Results of the two incidence screenings in the National Lung Screening Trial. N Engl J Med 2013;369:920-31.

7. Aberle DR, Adams AM, Berg CD, et al. Reduced lungcancer mortality with low-dose computed tomographic screening. N Engl J Med 2011;365:395-409.

8. Jemal A, Fedewa SA. Lung cancer screening with low-dose computed tomography in the United States-2010 to 2015. JAMA Oncol 2017;3:1278-81.

9. Pass HI, Beer DG, Joseph S, et al. Biomarkers and molecular testing for early detection, diagnosis, and therapeutic prediction of lung cancer. Thorac Surg Clin 2013;23:211-24.

10. Hassanein M, Callison JC, Callaway-Lane C, et al. The state of molecular biomarkers for the early detection of lung cancer. Cancer Prev Res (Phila) 2012;5:992-1006.

11. Kammer MN, Lakhani DA, Balar AB, et al. Integrated Biomarkers for the Management of Indeterminate Pulmonary Nodules. Am J Respir Crit Care Med 2021;204:1306-16.

12. Seijo LM, Peled N, Ajona D, et al. Biomarkers in lung cancer screening: achievements, promises, and challenges. 
J Thorac Oncol 2019;14:343-57.

13. Atwater T, Massion P. Biomarkers of risk to develop lung cancer in the new screening era. Ann Transl Med 2016;4:158.

14. Parikh R, Mathai A, Parikh S, et al. Understanding and using sensitivity, specificity, and predictive values. Indian J Ophthalmol 2008;56:45-50.

15. Hensing TA, Salgia R. Molecular biomarkers for future screening of lung cancer. J Surg Oncol 2013;108:327-33.

16. Boyle P, Chapman CJ, Holdenrieder S, et al. Clinical validation of an autoantibody test for lung cancer. Ann Oncol 2011;22:383-9.

17. Chapman CJ, Healey GF, Murray A, et al. EarlyCDTLung test; improved clinical utility through additional autoantibody assays. Tumour Biol 2012;33:1319-26.

18. Jett JR, Peek L, Fredericks L, et al. Audit of the autoantibody test, EarlyCDT-Lung, in 1600 patients: an evaluation of its performance in routine clinical practice. Lung Cancer 2014;83:51-5.

19. Wang J, Shivakumar S, Barker K, et al. Comparative study of autoantibody responses between lung adenocarcinoma and benign pulmonary nodules. J Thorac Oncol 2016;11:334-45.

20. Ajona D, Okroj M, Pajares M, et al. Complement C4dspecific antibodies for the diagnosis of lung cancer. Oncotarget 2017;9:6346-55.

21. Sozzi G, Boeri M, Rossi M, et al. Clinical utility of a plasma-based miRNA signature classifier within computed tomography lung cancer screening: a correlative MILD trial study. J Clin Oncol 2014;32:768-73.

22. Montani F, Marzi MJ, Dezi F, et al. miR-Test: a blood test for lung cancer early detection. J Natl Cancer Inst 2015;107:djv063.

23. Doseeva V, Colpitts T, Gao G, et al. Performance of a multiplexed dual analyte immunoassay for the early detection of non-small cell lung cancer. J Transl Med 2015;13:55.

24. Mazzone PJ, Wang X, Han X, et al. Evaluation of a serum lung cancer biomarker panel. Biomarker Insights 2018;13:1177271917751608.

25. Silvestri GA, Tanner NT, Kearney P, et al. Assessment of plasma proteomics biomarker's ability to distinguish benign from malignant lung nodules: results of the PANOPTIC (Pulmonary Nodule Plasma Proteomic Classifier) trial. Chest 2018;154:491-500.

26. Molina R, Marrades RM, Auge JM, et al. Assessment of a combined panel of six serum tumor markers for lung cancer. Am J Respir Crit Care Med 2016;193:427-37.
27. Vachani A, Pass HI, Rom WN, et al. Validation of a multiprotein plasma classifier to identify benign lung nodules. J Thorac Oncol 2015;10:629-37.

28. Trivedi NN, Arjomandi M, Brown JK, et al. Risk assessment for indeterminate pulmonary nodules using a novel, plasma-protein based biomarker assay. Biomed Res Clin Pract 2018. doi: 10.15761/brcp.1000173.

29. Cohen JD, Li L, Wang Y, et al. Detection and localization of surgically resectable cancers with a multi-analyte blood test. Science 2018;359:926-30.

30. Hulbert A, Jusue-Torres I, Stark A, et al. Early detection of lung cancer using DNA promoter hypermethylation in plasma and sputum. Clin Cancer Res 2017;23:1998-2005.

31. Weiss G, Schlegel A, Kottwitz D, et al. Validation of the SHOX2/PTGER4 DNA methylation marker panel for plasma-based discrimination between patients with malignant and nonmalignant lung disease. J Thorac Oncol 2017;12:77-84.

32. Ooki A, Maleki Z, Tsay JJ, et al. A panel of novel detection and prognostic methylated DNA markers in primary nonsmall cell lung cancer and serum DNA. Clin Cancer Res 2017;23:7141-52.

33. Mazzone PJ, Sears CR, Arenberg DA, et al. Evaluating molecular biomarkers for the early detection of lung cancer: when is a biomarker ready for clinical use? An official American Thoracic Society policy statement. Am J Respir Crit Care Med 2017;196:e15-e29.

34. Solassol J, Maudelonde T, Mange A, et al. Clinical relevance of autoantibody detection in lung cancer. J Thorac Oncol 2011;6:955-62.

35. Oncimmune. EarlyCDT. 2020. Available online: https:// oncimmune.com/products/earlyctd-lung. Accessed September 2020.

36. Blandin Knight S, Crosbie PA, Balata H, et al. Progress and prospects of early detection in lung cancer. Open Biol 2017;7:170070.

37. Massion PP, Healey GF, Peek LJ, et al. Autoantibody signature enhances the positive predictive power of computed tomography and nodule-based risk models for detection of lung cancer. J Thorac Oncol 2017;12:578-84.

38. Ajona D, Pajares MJ, Corrales L, et al. Investigation of complement activation product $\mathrm{C} 4 \mathrm{~d}$ as a diagnostic and prognostic biomarker for lung cancer. J Natl Cancer Inst 2013;105:1385-93.

39. Zaporozhchenko IA, Morozkin ES, Ponomaryova AA, et al. Profiling of 179 miRNA expression in blood plasma of lung cancer patients and cancer-free individuals. Sci Rep 2018;8:6348. 
40. Hasan N, Kumar R, Kavuru MS. Lung cancer screening beyond low-dose computed tomography: the role of novel biomarkers. Lung 2014;192:639-48.

41. Wozniak MB, Scelo G, Muller DC, et al. Circulating microRNAs as non-invasive biomarkers for early detection of non-small-cell lung cancer. PLoS One 2015;10:e0125026.

42. Chu GC, Lazare K, Sullivan F. Serum and blood based biomarkers for lung cancer screening: a systematic review. BMC Cancer 2018;18:181.

43. El-Khoury V, Schritz A, Kim SY, et al. Identification of a blood-based protein biomarker panel for lung cancer detection. Cancers (Basel) 2020;12:1629.

44. Atwater T, Cook CM, Massion P. The pursuit of noninvasive diagnosis of lung cancer. Semin Respir Crit Care Med 2016;37:670-80.

45. Genesys Biolabs. PAULA's Test. 2017. Available online: https://bloodtestforlungcancer.com/. Accessed September 2020.

46. Wu TH, Hsiue EH, Yang JC. Opportunities of circulating tumor DNA in lung cancer. Cancer Treat Rev 2019;78:31-41.

doi: $10.21037 /$ ccts-20-171

Cite this article as: Marmor HN, Zorn JT, Deppen SA, Massion PP, Grogan EL. Biomarkers in lung cancer screening: a narrative review. Curr Chall Thorac Surg 2023;5:5.
47. Kunnath AP, Priyashini T. Potential applications of circulating tumor DNA technology as a cancer diagnostic tool. Cureus 2019;11:e4907.

48. Chabon JJ, Hamilton EG, Kurtz DM, et al. Integrating genomic features for non-invasive early lung cancer detection. Nature 2020;580:245-51.

49. Cristiano S, Leal A, Phallen J, et al. Genome-wide cellfree DNA fragmentation in patients with cancer. Nature 2019;570:385-9.

50. Liang $W$, Zhao $Y$, Huang $W$, et al. Non-invasive diagnosis of early-stage lung cancer using high-throughput targeted DNA methylation sequencing of circulating tumor DNA (ctDNA). Theranostics 2019;9:2056-70.

51. Kerr KM, Galler JS, Hagen JA, et al. The role of DNA methylation in the development and progression of lung adenocarcinoma. Dis Markers 2007;23:5-30.

52. Li Z, Shu J, Yang B, et al. Emerging non-invasive detection methodologies for lung cancer (Review). Oncol Lett 2020;19:3389-99.

53. Robles AI, Harris CC. Integration of multiple "Omic" biomarkers: a precision medicine strategy for lung cancer. Lung Cancer 2017;107:50-8. 